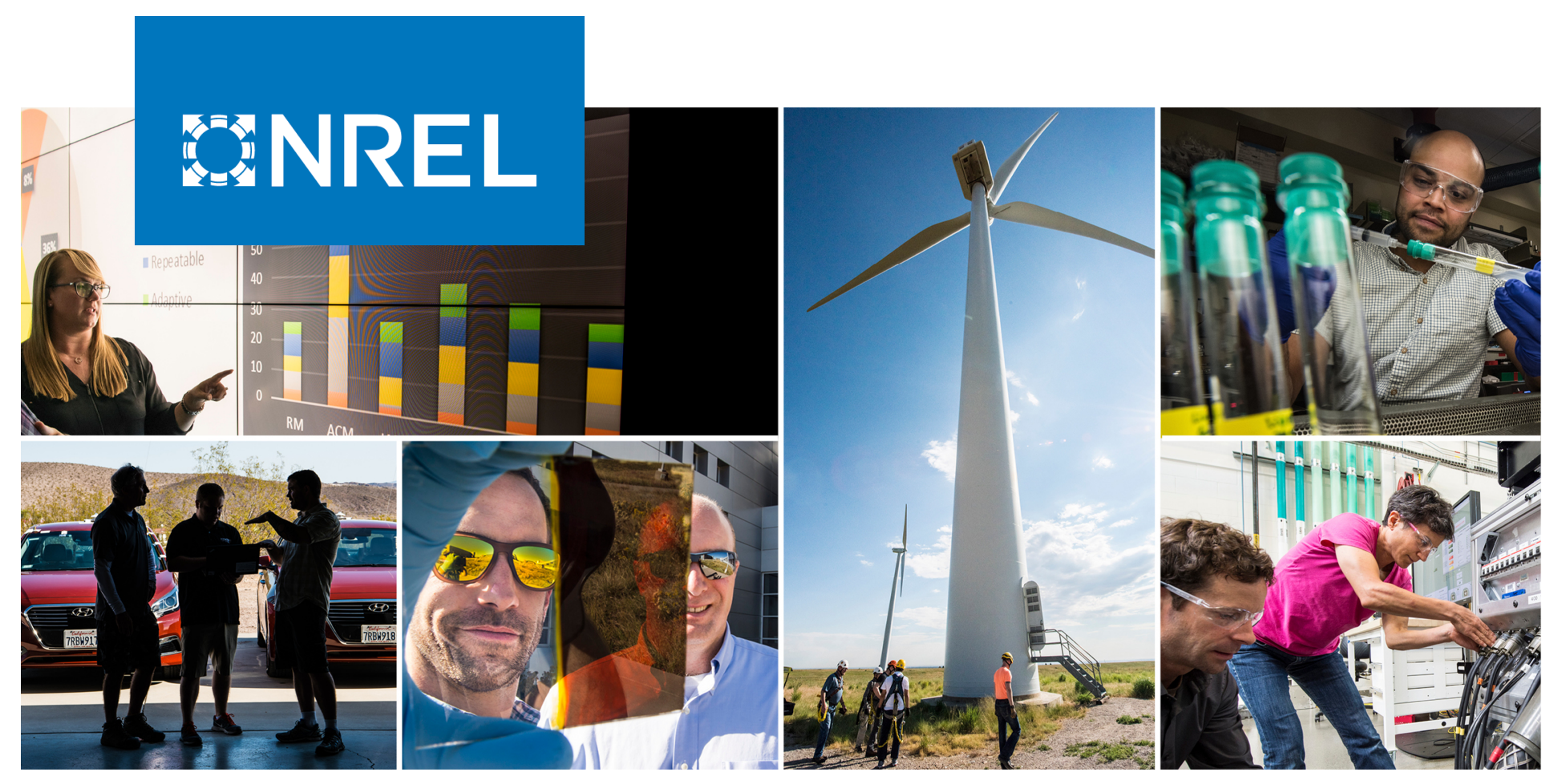

\title{
A High-Speed High-Power-Density Non- Heavy Rare-Earth Permanent Magnet Traction Motor
}

\section{Preprint}

Tsarafidy Raminosoa, ${ }^{1}$ Randy Wiles, ${ }^{1} \mathrm{~J}$. Emily Cousineau, ${ }^{2}$ Kevin Bennion, ${ }^{2}$ and Jon Wilkins ${ }^{1}$

1 Oak Ridge National Laboratory

2 National Renewable Energy Laboratory

Presented at the IEEE Energy Conversion Congress \& Exposition (ECCE) October 11-15, 2020

NREL is a national laboratory of the U.S. Department of Energy Office of Energy Efficiency \& Renewable Energy

Operated by the Alliance for Sustainable Energy, LLC

This report is available at no cost from the National Renewable Energy Laboratory (NREL) at www.nrel.gov/publications.

\section{Conference Paper}

NREL/CP-5400-75994

October 2020 


\title{
BNREL
}

\section{A High-Speed High-Power-Density Non- Heavy Rare-Earth Permanent Magnet Traction Motor}

\section{Preprint}

\author{
Tsarafidy Raminosoa, ${ }^{1}$ Randy Wiles, ${ }^{1} \mathrm{~J}$. Emily Cousineau, ${ }^{2}$ \\ Kevin Bennion, ${ }^{2}$ and Jon Wilkins ${ }^{1}$
}

\author{
1 Oak Ridge National Laboratory \\ 2 National Renewable Energy Laboratory
}

\section{Suggested Citation}

Raminosoa, Tsarafidy, Randy Wiles, J. Emily Cousineau, Kevin Bennion, and Jon Wilkins. 2020. A High-Speed High-Power-Density Non-Heavy Rare-Earth Permanent Magnet Traction Motor: Preprint. Golden, CO: National Renewable Energy Laboratory. NREL/CP-5400-75994. https://www.nrel.gov/docs/fy21osti/75994.pdf.

(C) 2020 IEEE. Personal use of this material is permitted. Permission from IEEE must be obtained for all other uses, in any current or future media, including reprinting/republishing this material for advertising or promotional purposes, creating new collective works, for resale or redistribution to servers or lists, or reuse of any copyrighted component of this work in other works.

NREL is a national laboratory of the U.S. Department of Energy Office of Energy Efficiency \& Renewable Energy Operated by the Alliance for Sustainable Energy, LLC

This report is available at no cost from the National Renewable Energy Laboratory (NREL) at www.nrel.gov/publications.

Contract No. DE-AC36-08GO28308
Conference Paper

NREL/CP-5400-75994

October 2020

National Renewable Energy Laboratory 15013 Denver West Parkway Golden, CO 80401

303-275-3000 • www.nrel.gov 


\section{NOTICE}

This work was authored in part by the National Renewable Energy Laboratory, operated by Alliance for Sustainable Energy, LLC, for the U.S. Department of Energy (DOE) under Contract No. DE-AC36-08GO28308. Funding provided by U.S. Department of Energy Office of Energy Efficiency and Renewable Energy Vehicle Technologies Office. The views expressed herein do not necessarily represent the views of the DOE or the U.S. Government. The U.S. Government retains and the publisher, by accepting the article for publication, acknowledges that the U.S. Government retains a nonexclusive, paid-up, irrevocable, worldwide license to publish or reproduce the published form of this work, or allow others to do so, for U.S. Government purposes..

This report is available at no cost from the National Renewable Energy Laboratory (NREL) at www.nrel.gov/publications.

U.S. Department of Energy (DOE) reports produced after 1991 and a growing number of pre-1991 documents are available free via www.OSTI.gov.

Cover Photos by Dennis Schroeder: (clockwise, left to right) NREL 51934, NREL 45897, NREL 42160, NREL 45891, NREL 48097, NREL 46526.

NREL prints on paper that contains recycled content. 


\title{
A High-Speed High-Power-Density Non-Heavy Rare- Earth Permanent Magnet Traction Motor
}

\author{
Tsarafidy Raminosoa \\ Power Electronics and Electric \\ Machinery Group \\ Oak Ridge National Laboratory \\ Knoxville, Tennessee, USA \\ raminosoat@ornl.gov
}

\author{
Randy Wiles \\ Power Electronics and Electric \\ Machinery Group \\ Oak Ridge National Laboratory \\ Knoxville, Tennessee, USA \\ wilesrh@ornl.gov
}

\author{
J. Emily Cousineau \\ Center for Integrated Mobility \\ Sciences \\ National Renewable Energy \\ Laboratory \\ Golden, Colorado, USA \\ Emily.Cousineau@nrel.gov
}

\author{
Kevin Bennion \\ Center for Integrated Mobility \\ Sciences \\ National Renewable Energy \\ Laboratory \\ Golden, Colorado, USA \\ Kevin.Bennion@nrel.gov
}

\author{
Jon Wilkins \\ Power Electronics and Electric Machinery Group \\ Oak Ridge National Laboratory \\ Knoxville, Tennessee, USA \\ wilkinsjp@ornl.gov
}

\begin{abstract}
There has been a global push for higher torque density and lower cost traction motors. The use of non-heavy rareearth (non-HRE) permanent magnet materials in traction motors are being investigated for the sustainability, profitability and affordability of electric vehicles and to broaden their adoption. A 20,000-rpm permanent magnet traction motor using non-HRE magnet materials is proposed. A dual three-phase winding configuration driven by a segmented dual three-phase drive is proposed to reduce the current ripple, and as a result, the DC Link capacitor, as well as to ease the voltage constraint at high speed and eliminate any risk of uncontrolled regeneration. Furthermore, the dual winding configuration enables a fault tolerant design which is useful for reliability. The paper presents comprehensive electromagnetic, thermal and mechanical designs and analyses using an integrated approach. The results have shown that the design is robust against demagnetization and confirmed its thermal and mechanical viability.
\end{abstract}

Keywords- traction motors, non-heavy rare-earth motors, electric vehicle

\section{INTRODUCTION}

There has been a steady increase in global $\mathrm{CO}_{2}$ emission since 1900 with a sharp rise since 1945[1][2]. In the US, the transportation sector is responsible of $28 \%$ of the greenhouse gas emissions [3]. These observations have led to global environmental consciousness and tighter regulations of $\mathrm{CO}_{2}$ emissions in several countries, resulting in the expansion of the electrification of passenger and commercial vehicles.
TABLE I. KEY SPECIFICATIONS

\begin{tabular}{|l|c|}
\hline Peak power $(\mathrm{kW})$ & 100 \\
\hline Continuous power $(\mathrm{kW})$ & 55 \\
\hline Maximum speed $(\mathrm{rpm})$ & $\leqslant 20,000$ \\
\hline Battery operating voltage $(\mathrm{Vdc})$ & 650 \\
\hline Power factor & $>0.8$ \\
\hline Maximum current $(\mathrm{A})$ & 600 \\
\hline Maximum efficiency $(\%)$ & $>97$ \\
\hline Torque ripple $(\%)$ & $\leqslant 5$ \\
\hline Maximum temperature $\left({ }^{\circ} \mathrm{C}\right)$ & 150 \\
\hline $\begin{array}{l}\text { Active volume including } \\
\text { end windings }(@ 50 \mathrm{~kW} / \mathrm{l})(\mathrm{Liter})\end{array}$ & 2 \\
\hline
\end{tabular}

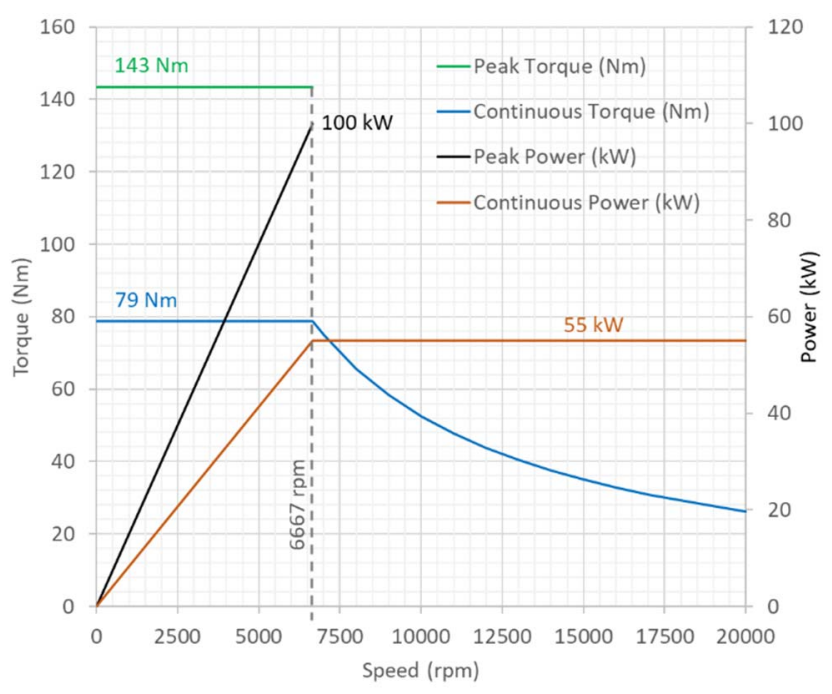

Fig. 1. Summary of specifications. 
Due to their high torque, power density and excellent efficiency, most electric traction motors currently in production are permanent magnet synchronous motors, which use costly heavy rare-earth magnet material such as Dysprosium (Dy). However, the price and supply of Dysprosium have historically shown volatilities. To deal with these risks, substantial progress has been made in the permanent magnet (PM) material technologies to significantly reduce or eliminate Dysprosium from the material composition. Dysprosium-free PM materials are now commercialized by major suppliers [4-6]. This can help lower the cost of traction motors and accelerate the market penetration of electric vehicles. However, Dy-free PM materials have lower coercivity, thus they are more prone to demagnetization, compared to conventional heavy rare-earth counterparts. Therefore, special attention should be paid to demagnetization when designing Dy-free PM motors.

For battery electric vehicles, research and development efforts on traction motors are currently pushed toward highpower density to maximize passenger comfort and cargo space, while keeping high efficiency to maximize the vehicle's range [7]. To this end, a high-speed (up to 20,000 rpm) non-heavy rareearth permanent magnet traction motor with a peak power of 100 $\mathrm{kW}$ is designed to target the U.S. Drive specifications presented in Table I and Fig.1. The motor uses a permanent magnet material free of Dysprosium (Fig. 2) [8]. An outer rotor Halbach Surface Permanent Magnet with concentrated tooth winding (Fig. 3) was selected for the following reasons:

1) It offers the opportunity to integrate the power electronics within the inner hollow volume of the stator,

2) Magnet retention against centrifugal force is naturally provided by the rotor yoke and the rotor support structure. In addition, the rotor has a robust continuous construction as opposed to a spoke PM rotor which has a segmented rotor construction or an interior PM rotor which relies on thin lamination bridges and posts for structural integrity,

3) The airgap radius is at the outermost possible location which helps maximize the torque density. In fact, a previous study has shown that this topology has the highest power density among several potential candidates [9],

4) Tooth winding is chosen for the associated high direct inductance that improves flux weakening capability. Such winding also enables low torque ripple.

A dual three-phase winding configuration is proposed so the motor can be powered by a dual three-phase segmented drive featuring interleaved switching to reduce the current ripple and thereby the DC Link capacitor [10] (Fig. 4). This winding configuration also halves the back electromotive force (EMF) on each set of windings, and therefore eases the voltage constraint at high speed and eliminates uncontrolled regeneration. Moreover, the dual winding configuration enables fault tolerance which, although not required, is useful for operating at reduced performance to allow the vehicle to continue to move.

\section{Electromagnetic Characterization of the Design}

The designed 18 slot -20 pole motor with the dimensions and the different materials used is shown in Fig. 3. Since nonHRE PMs are more prone to demagnetization than their conventional counterparts with HRE, special attention must be paid to the demagnetization risk. Hence, a Halbach magnetization arrangement was chosen to: a) maximize the airgap flux density; and b) reinforce the resistance to demagnetization. The magnetic loading under peak torque condition is presented in Fig. 5. The torque waveform was calculated and is presented in Fig. 6 with an average torque of $163 \mathrm{Nm}$ and only $1.3 \%$ ripple, the design meets the peak power and torque quality requirements. The line-to-line open-circuit voltage waveform at $20,000 \mathrm{rpm}$ is shown in Fig. 7. It is very close to the sinusoidal shape and its peak value is below the $650 \mathrm{~V}$ DC-link voltage. This confirms that there is no risk of uncontrolled regeneration. To evaluate the risk of demagnetization, extreme scenarios of transient three-phase short-circuit fault and purely negative peak current were simulated at 20,000 rpm using Finite Element Analysis (FEA) featuring dynamic non-linear demagnetization modeling. The assumed temperature of the permanent magnets is $150^{\circ} \mathrm{C}$. The resulting reduction of the torque capability can be observed in Fig. 8. Figure 8(a) compares the effects of a three-phase shortcircuit fault and purely negative d-axis current. The three-phase short circuit fault is more severe and causes $12 \%$ torque reduction. The order of occurrence of the two types of faults (Fig. 8(a)) and the timing of the three-phase short-circuit fault (Fig. 8(b)) do not affect the torque reduction. Moreover, if several subsequent faults are applied, the torque stabilizes at 144 $\mathrm{Nm}$ and still meets the peak torque requirement (Fig. 8(c)). This confirms that the design is resistant to demagnetization and a $12 \%$ design margin was introduced to compensate for the worst case demagnetization as shown in Fig. 6 [9]. Finally, the calculated active volume is $2.48 \mathrm{~L}$. This includes the end windings assumed as arc-shaped (Fig. 3) but excludes the stator inner hollow space where the power electronics will be integrated.

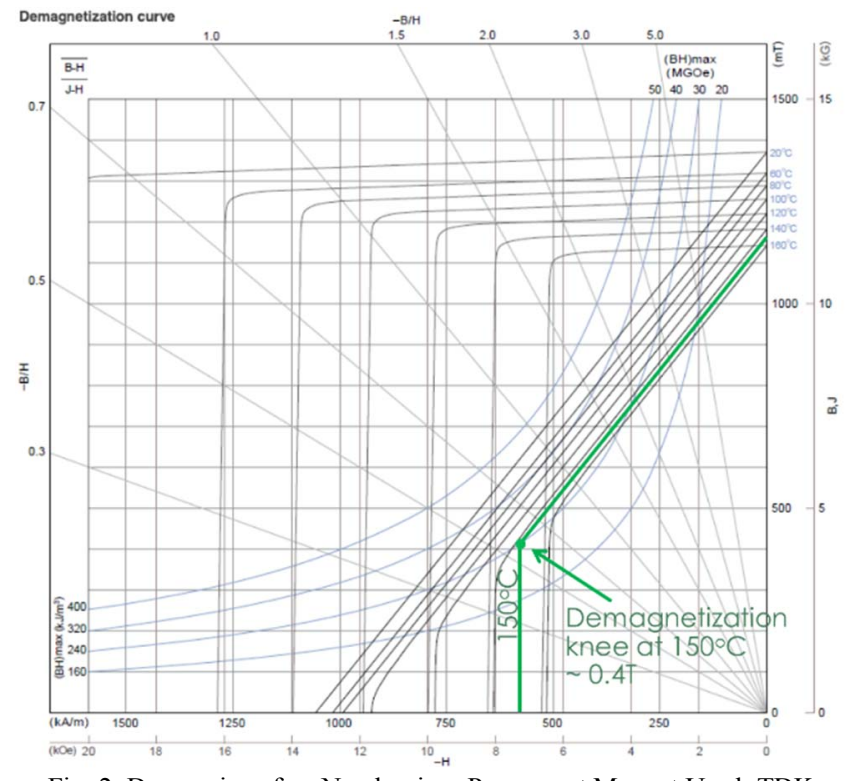

Fig. 2. Dysprosium-free Neodymium Permanent Magnet Used: TDK NEOREC45MHF [8] 


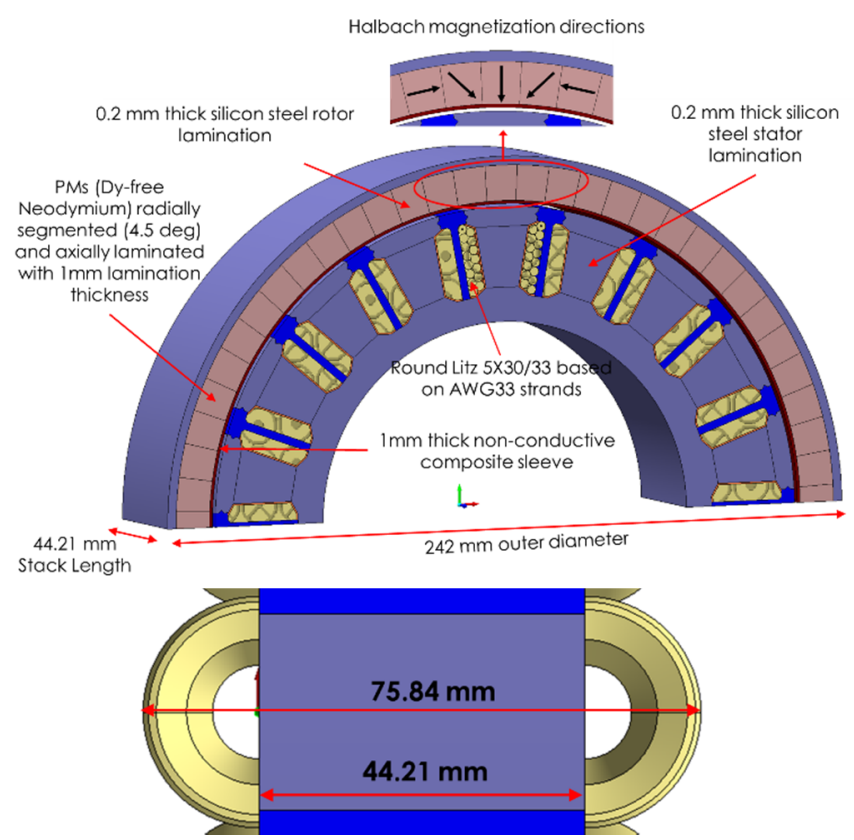

Fig. 3. Heavy Rare-Earth-Free Outer Rotor Permanent Magnet Traction Motor.
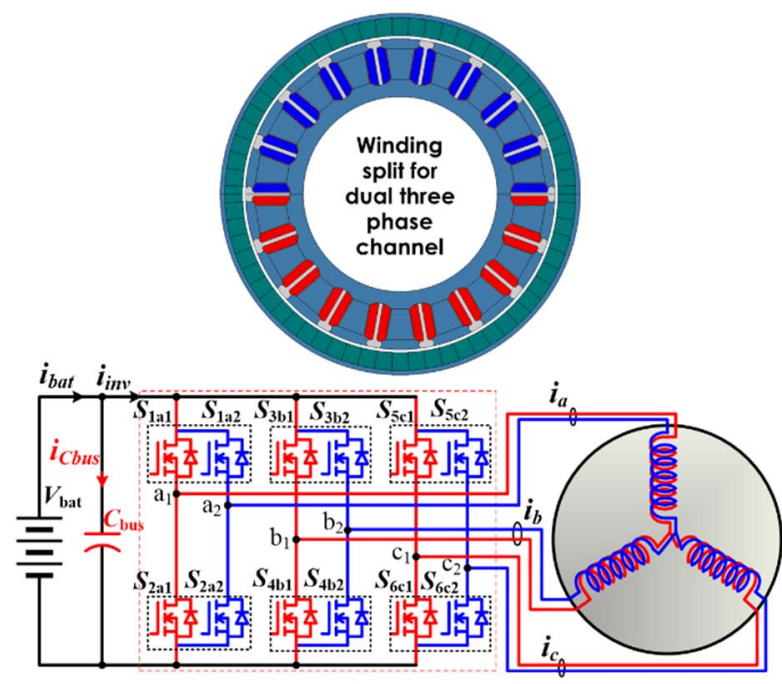

Segmented 3-phase inverter

Fig. 4. Segmented drive of a dual three-phase channel motor enabling reduction of DC bus capacitor ripple current [10]

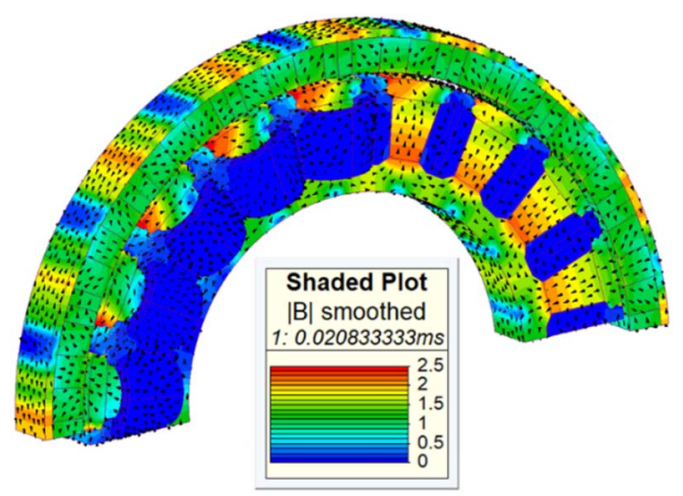

Fig. 5. Magnetic loading under peak torque condition.

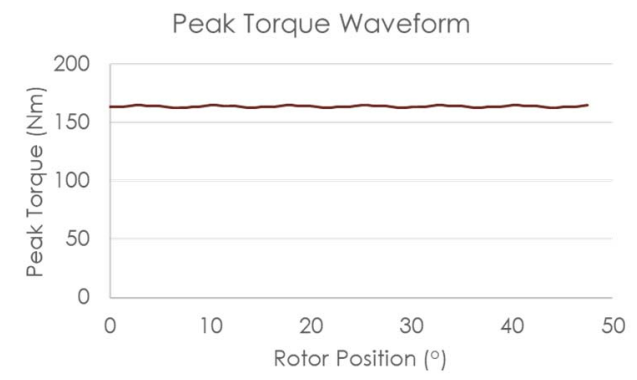

Fig. 6. Peak torque waveform with $12 \%$ design margin.

Line to Line Back EMF at 20,000rpm

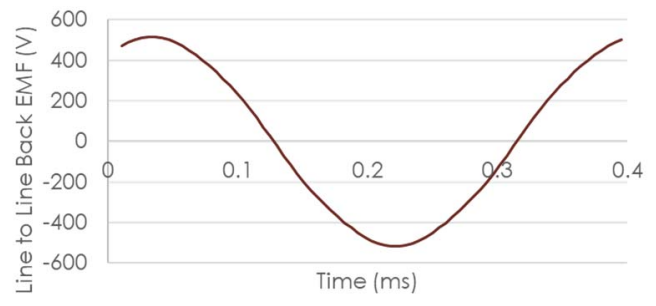

Fig. 7. Line to line back EMF waveform at 20,000rpm.

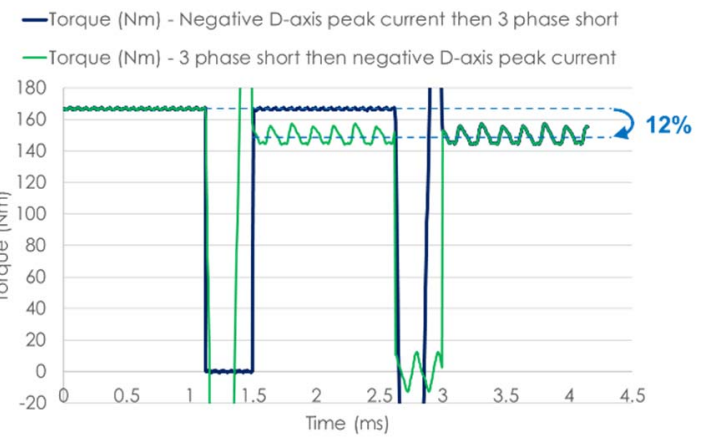

(a)

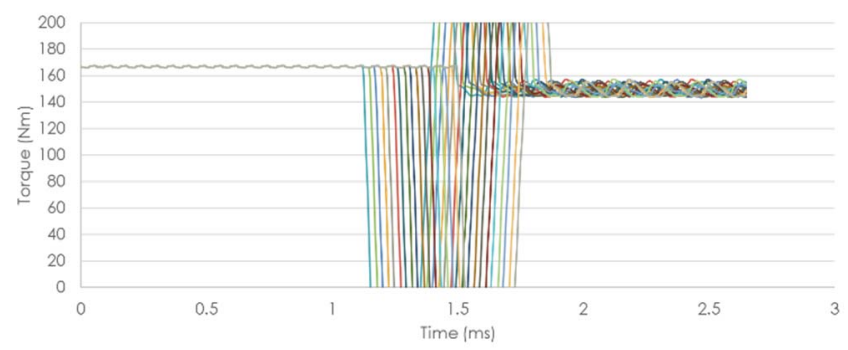

(b)

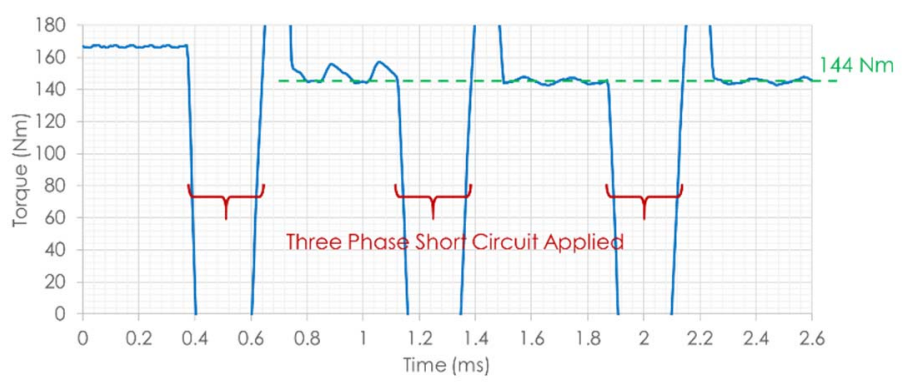

(c)

Fig. 8. Demagnetization Resistance Under Transient Three-Phase ShortCircuit at 20,000rpm and with a PM Temperature of $150^{\circ} \mathrm{C}$ : (a) Effect of the timing of the fault; (b) Effect of purely negative d-axis peak current versus three-phase short circuit; (c) Effect of subsequent faults. 


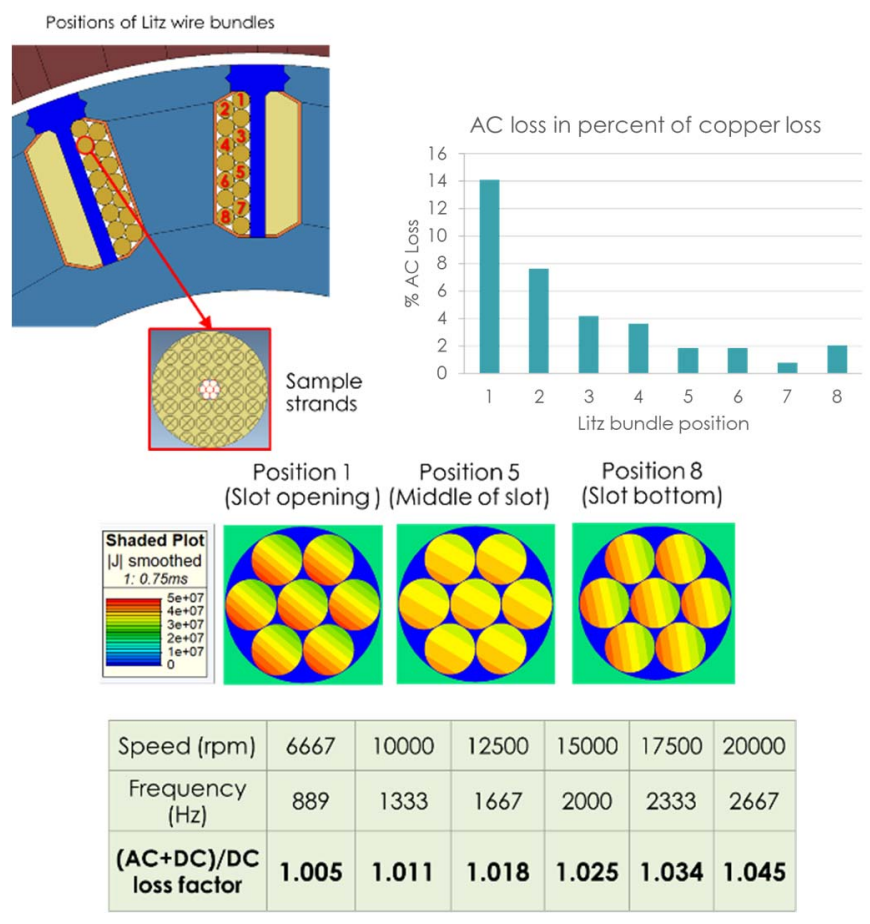

Fig. 9. AC Loss Calculation.

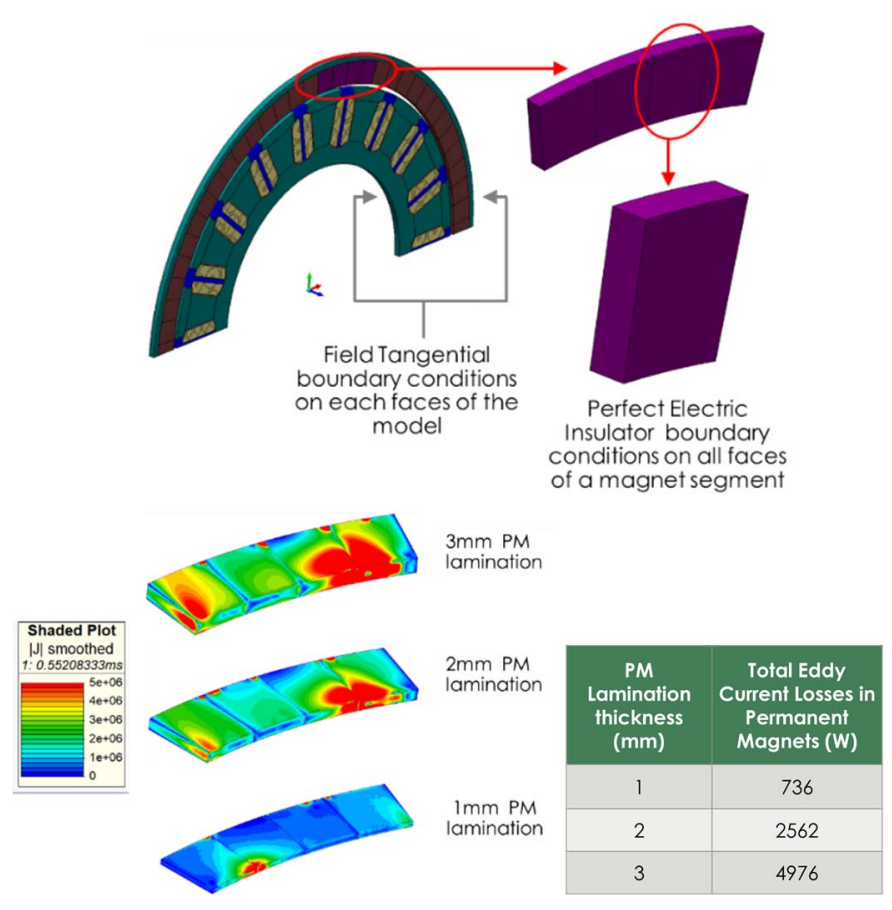

Fig. 10. Calculation of PM Eddy Current Loss.

\section{A. AC Loss}

Given the high operating frequency, especially at high speeds, $5 \times 30 / 33$ round Litz wire based on AWG33 strands was necessary for the stator winding [11]. The induced eddy current loss was evaluated on a sample of strands for all the positions of the Litz wire bundles on a tooth-wound coil as described in Fig. $9[12,13]$. Two-dimensional finite element analyses were carried out for a given current at 20,000 rpm. The average of the AC loss factors calculated on the bundles is used as the overall $\mathrm{AC}$ loss factor. For other speeds, the AC loss factor is calculated by scaling the AC component of the loss with the speed squared. The calculated $\mathrm{AC}$ loss factors for a range of speeds are presented in Fig. 9: the fraction of AC loss is less than 5\% of the DC Copper loss due to the choice of a Litz wire based on AWG33 strands.

\section{B. Eddy Current Loss in Permanent Magnets}

The rotor uses a four-segment Halbach arrangement per pole with laminated permanent magnets (Fig. 3). Hence the magnets are segmented both circumferentially and axially and the eddy current flow is three-dimensional. In order to accurately calculate the eddy current loss, a three-dimensional finite element model was created with an axial length equal to the thickness of a PM lamination as described in (Fig. 10). PM lamination thicknesses of 1,2 and $3 \mathrm{~mm}$ were analyzed. The eddy current losses in PMs are evaluated for one operating point (600 Arms at 20,000 rpm). For other operating points, the losses are scaled with the current squared and speed squared. The calculated total eddy current loss is presented in Fig. 10. A PM lamination thickness of $1 \mathrm{~mm}$ was chosen to minimize the eddy current loss while ensuring manufacturability [14].

\section{Electromagnetic Performance}

The calculated torque, power, efficiency and power factor of the of the design are presented in Fig. 11. It shows that the design can provide the required continuous $55 \mathrm{~kW}$ power with $12 \%$ design margin for the whole speed range while staying within the current and voltage limits. Further, the efficiency specification is met, and the motor has a very good efficiency across the whole speed range ( $98 \%$ at base speed and $94.7 \%$ at top speed).

Given the high operating frequency, commercially available thin-gauge silicon steel laminations were considered [15-18]. The various electromagnetic loss components are presented in Fig. 12 for a $0.2 \mathrm{~mm}$ thick stator and rotor laminations [16]. The stator iron loss is the predominant loss component across the whole speed range. The magnet eddy current losses are kept low even at high speed due to the segmentation and lamination of the permanent magnets. Besides, all the loss components are the highest at 20,000 rpm operation, resulting in highest heat losses and temperatures at this operating condition. Lastly, analyses have indicated that the tooth shoes and tooth shanks have the highest loss density, and as a result, they are potential hot spots. Fig. 13 shows the iron loss and efficiency for various commercially available thin gauge silicon steel lamination thicknesses: $0.25 \mathrm{~mm}$ Di-Max HF-10 from AK Steel [15], 0.2 $\mathrm{mm}$ powercore ${ }^{\circledR} 020-150$ Y320 from Thyssenkrupp [16] and $0.178 \mathrm{~mm}$ Arnon 7 from Arnold Magnetics [17,18]. It suggests that the $0.2 \mathrm{~mm}$ thick silicon steel is the best compromise between iron loss and cost. 


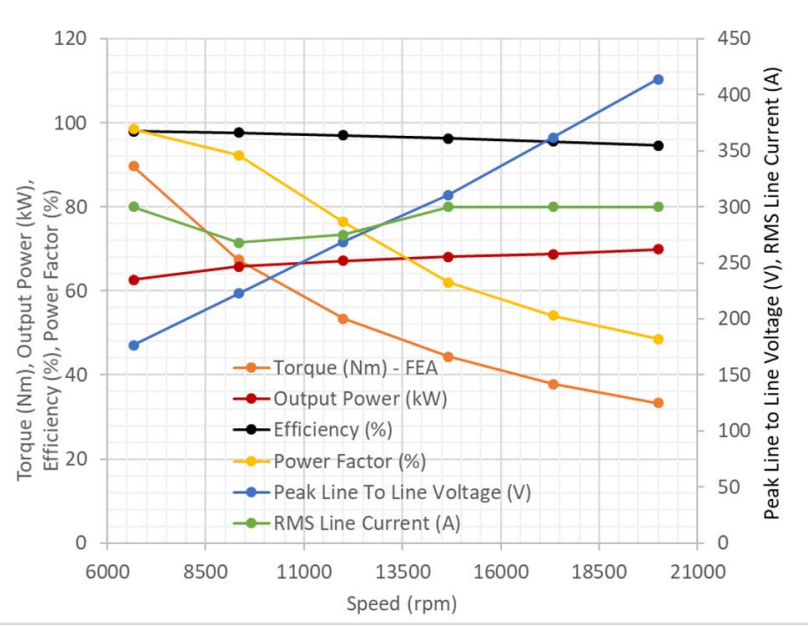

Fig. 11. Performance Under 55kW Continuous Operation for $0.2 \mathrm{~mm}$ lamination thickness.

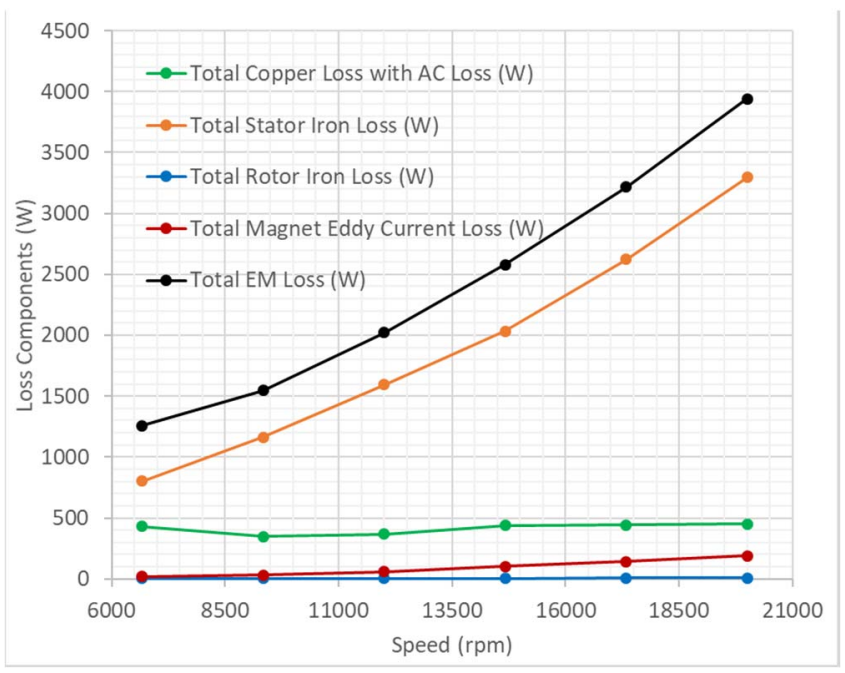

Fig. 12. Electromagnetic loss components for $0.2 \mathrm{~mm}$ lamination thickness.

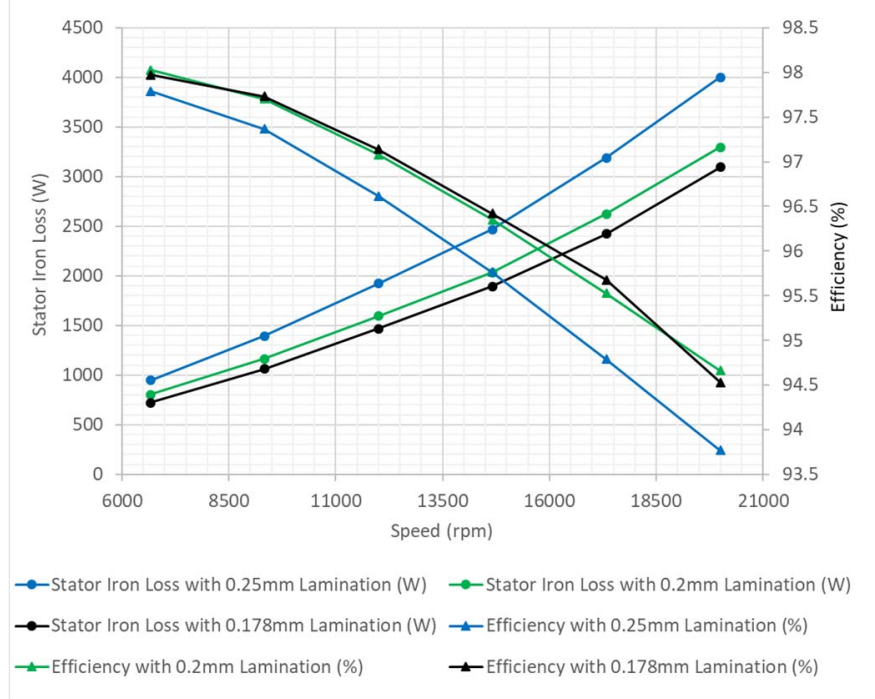

Fig. 13. Iron Loss and Efficiency for various lamination thicknesses.

\section{MECHANICAL ViABILITY}

The overall mechanical assembly is presented in Fig. 14. Mechanical stress analyses have been conducted at the maximum speed of $20,000 \mathrm{rpm}$ to verify the mechanical integrity of the assembly. The results are shown in Fig. 15.

According to Fig. 15(a), the stresses are below $860 \mathrm{MPa}$. Commercially available high strength stainless steel with a tensile strength of $1300 \mathrm{MPa}$ and yield strength of $1000 \mathrm{MPa}$ can be used for the rotor support [19]. Fig.15(b) shows a maximum displacement of $0.22 \mathrm{~mm}$. It should be noted that the displacement is radially outward and increases the designed $1 \mathrm{~mm}$ mechanical airgap. Hence, there is no risk of rubbing between the rotor and stator. Further improvement of the rotor support is being carried out to reduce the deformation. The above results support the viability of the proposed rotor assembly concept.

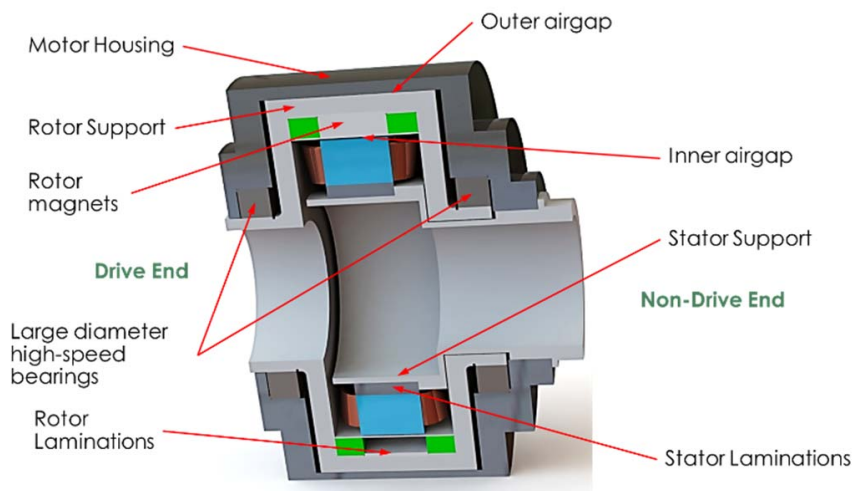

Fig. 14. Mechanical assembly.

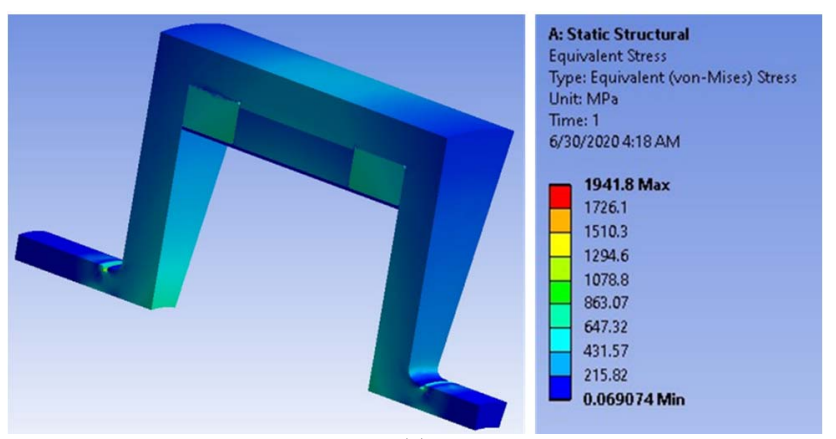

(a)

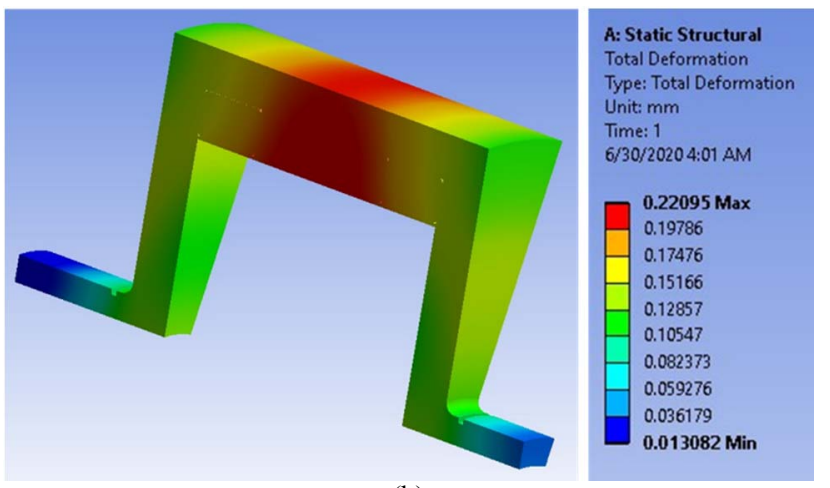

(b)

Fig. 15. Mechanical Stress Analysis at 20,000 rpm: (a) Equivalent Stress; (b) Deformation. 


\section{THERMAL VIABILITY}

Thermal modeling and analysis focused on threedimensional finite element analysis to evaluate impacts and interactions between passive thermal design elements and the active cooling design. The thermal model was developed using material properties from literature [11,20,21]. This included evaluating the thermal impacts of alternative materials (such as lamination materials), active cooling locations, and active cooling heat transfer coefficients to identify cooling performance metrics. The thermal approach looked at applying cooling as close as possible to the heat generation sources in the windings and the magnets. The windings were cooled by using a $3 \mathrm{D}$ printed ceramic heat exchanger similar to [22]. The phase separators are converted into heat exchangers. The magnets were cooled using an oil flow through the rotor. The combined approach is very well suited to cooling the magnets, windings, stator yoke, and tooth tips as illustrated in Fig. 16. The preliminary results presented in Fig. 17 show that, with the combined cooling approach, the maximum temperature reaches about $163^{\circ} \mathrm{C}$. With additional refinement of the cooling design, further temperature reductions are expected. Table II compares the maximum temperatures in the motor resulting from the different losses due to varying lamination materials. While thinner laminations reduce the stator iron loss, they tend to be more expensive and their saturation flux density is lower. This results in the need for higher current, and consequently more losses in the in the windings. Table II also highlights a case where the boundary condition representing the rotor cooling was removed. Although the magnet temperature increases dramatically compared to a rotor with active cooling, the temperature is below the temperature limit of $150^{\circ} \mathrm{C}$. Removing the requirement for rotor cooling benefits the motor in terms of reduced complexity and cost.

TABLE II. IMPACT OF LAMINATION THICKNESS ON MAXIMUM TEMPERATURE

\begin{tabular}{|c|c|c|c|c|}
\hline \multirow{2}{*}{$\begin{array}{c}\text { Lamination } \\
\text { Thickness (mm) }\end{array}$} & \multicolumn{3}{|c|}{ Maximum Temperature $\left({ }^{\circ} \mathrm{C}\right)$} & \multirow[b]{2}{*}{ Notes } \\
\hline & Magnets & Stator & Windings & \\
\hline 0.250 & 77.5 & 180 & 176 & \\
\hline 0.200 & 76.1 & 162 & 163 & \\
\hline 0.178 & 75.7 & 156 & 160 & \\
\hline 0.200 & 135 & 167 & 167 & No rotor cooling \\
\hline
\end{tabular}

\section{CONCLUSION}

A high-speed non-heavy rare-earth outer rotor Halbach surface PM traction motor was designed with an integrated approach considering the electromagnetic, thermal and mechanical aspects to meet an aggressive set of specifications. The design meets the $100 \mathrm{~kW}$ peak $-55 \mathrm{~kW}$ continuous power, torque ripple, current, voltage and efficiency requirements. Furthermore, the design is robust against demagnetization even under the worst-case scenarios. Given the high operating frequency, elaborate winding $\mathrm{AC}$ loss and PM eddy current loss models were developed to accurately predict these critical loss components and ensure a reliable input to the thermal analyses. Although the very aggressive volume specification is not met, the calculated hot spot temperature is close to the specification, and mechanical stress analyses have confirmed the viability of the design. Moreover, the possibility of avoiding active cooling of the rotor greatly simplifies the integration of the cooling system. Further refinement of 1) the mechanical design to reduce the deformation at high speed; 2) the cooling system design to reduce the hot spot temperature down to $150^{\circ} \mathrm{C}$; and 3 ) the integration of the cooling system to the assembly are currently being carried out.
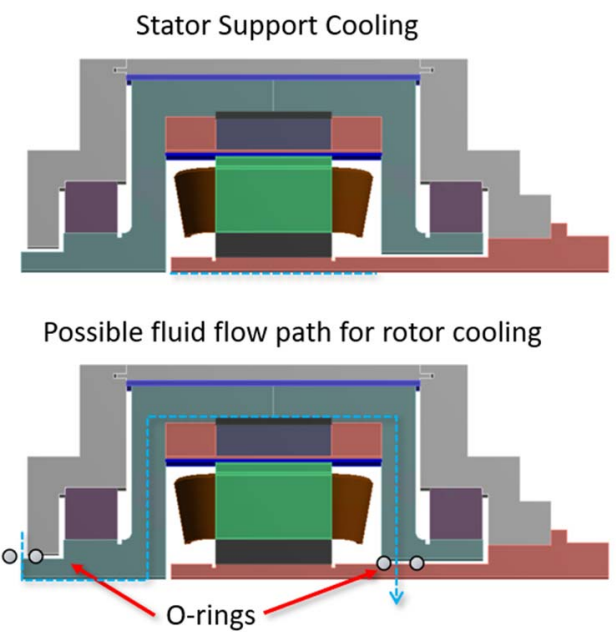

(a)

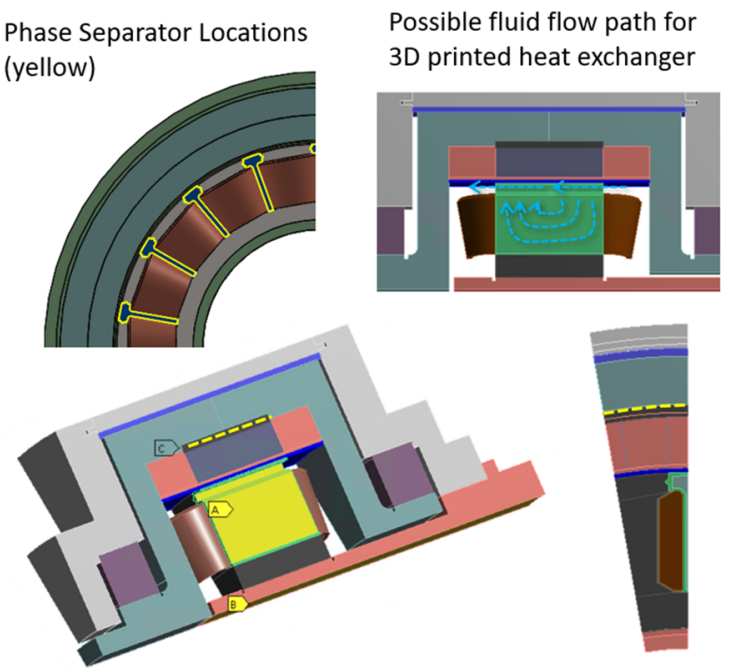

(b)

Fig. 16. Cooling Strategy: (a) Stator Support and Rotor Cooling; (B) Slot Heat Exchanger.
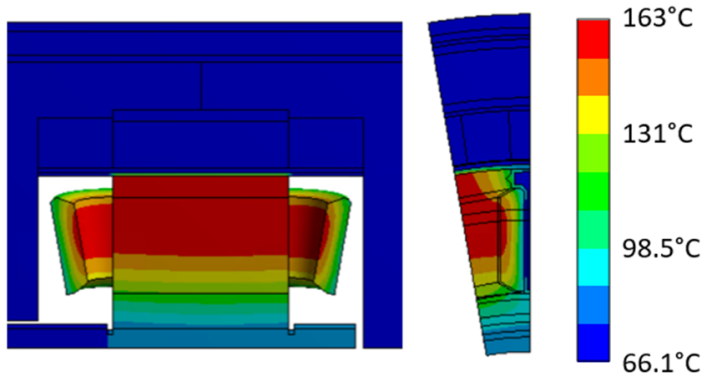

Fig. 17. Temperature Distribution at 55kW-20,000rpm using $0.2 \mathrm{~mm}$ lamination material. 


\section{ACKNOWLEDGMENT}

This material is based upon work supported by the U.S. Department of Energy, Office of Energy Efficiency and Renewable Energy, Vehicle Technologies Office under contract number DE-AC05-00OR22725. The authors would like to thank the U.S. Department of Energy's Susan Rogers, Oak Ridge National Laboratory's Burak Ozpineci, and National Renewable Energy Laboratory's Sreekant Narumanchi for their guidance and support.

\section{REFERENCES}

[1] Global Greenhouse Gas Emissions Data, https://www.epa.gov/ghgemissions/global-greenhouse-gas-emissionsdata

[2] T. A. Boden, R. J. Andres, and G. Marland, "Global, Regional, and National Fossil-Fuel CO2 Emissions (1751 - 2014) (V. 2017)”, United States: N. p., 2017. Web. doi:10.3334/CDIAC/00001_V2017.

[3] Inventory of U.S. Greenhouse Gas Emissions and Sinks, https://www.epa.gov/ghgemissions/inventory-us-greenhouse-gasemissions-and-sinks

[4] Arnold Magnetic's Grain Boundary Diffused Neo Catalog, https://www.arnoldmagnetics.com/wp-content/uploads/2019/06/ArnoldGrain-Boundary-Diffused-Neo-Catalog.pdf

[5] TDK Neodymium Magnets Catalog, https://product.tdk.com/info/en/products/magnet/magnet/neodymium/cat alog.html

[6] Shin-Etsu's N Series Neodymium Magnets, https://www.shinetsu-rareearth-magnet.jp/e/products/chart_nd.html

[7] Electrical and Electronics Technical Team Roadmap Roadmap, US DRIVE, October 2017, https://www.energy.gov/sites/prod/files/2017/11/f39/EETT\%20Roadma p\%2010-27-17.pdf

[8] TDK Dysprosium free Neodymium magnet at https://product.tdk.com/info/en/catalog/datasheets/magnet_neo_neorec4 5mhf_en.pdf

[9] Tsarafidy Raminosoa, Tolga Aytug, "Impact of Ultra-Conducting Winding on the Power Density and Performance of Non-Heavy Rare Earth Traction Motors," 2019 IEEE International Electric Machines \& Drives Conference (IEMDC), 2019.

[10] G. Su and L. Tang, "A segmented traction drive system with a small dc bus capacitor," 2012 IEEE Energy Conversion Congress and Exposition (ECCE), Raleigh, NC, 2012, pp. 2847-2853, doi: 10.1109/ECCE.2012.6342375.
[11] New England Wire Technologies, Litz Wire Technical Information, 2003, http://www.litzwire.com/nepdfs/Litz_Technical.pdf

[12] Tsarafidy Raminosoa, Ayman M. El-Refaie, Di Pan, Kum-Kang Huh, James P. Alexander, Kevin Grace, Stefan Grubic, Steven Galioto, Patel B. Reddy, Xiaochun Shen, "Reduced Rare-Earth Flux-Switching Machines for Traction Applications," IEEE Transactions on Industry Applications, vol. 51, no. 4, pp. 2959-2971, July-Aug. 2015, doi: 10.1109/TIA.2015.2397173.

[13] Tsarafidy Raminosoa, David A. Torrey, Ayman M. El-Refaie, Kevin Grace, Di Pan, Stefan Grubic, Karthik Bodla, Kum-Kang Huh, "Sinusoidal Reluctance Machine With DC Winding: An Attractive NonPermanent-Magnet Option," IEEE Transactions on Industry Applications, vol. 52, no. 3, pp. 2129-2137, May-June 2016, doi: 10.1109/TIA.2015.2512521.

[14] Arnold Magnetics'L Type Laminated Magnets, https://www.arnoldmagnetics.com/products/l-type-laminated-magnets/.

[15] AK Steel DI-MAX HF-10, https://www.aksteel.com/sites/default/files/2019-10/di-max-hf-10.pdf

[16] Thyssenkrupp's powercore ${ }^{\circledR}$ 020-150Y320, https://www.thyssenkruppsteel.com/media/content_1/publikationen/produktinformationen/powerc ore no/thyssenkrupp powercore 020150y320_product_information_steel_en.pdf

[17] Arnold Magnetic's Arnon 7 Non Grain Oriented Electrical Silicon Steel Magnetization Chart, https://www.arnoldmagnetics.com/wpcontent/uploads/2017/10/Arnon-7-NGOES-Magnetization-Curve-1.pdf

[18] Arnold Magnetic's Arnon 7 Non Grain Oriented Electrical Silicon Steel Core Loss Chart, https://www.arnoldmagnetics.com/wpcontent/uploads/2017/10/Arnon-7-NGOES-Core-Loss-Curve-1.pdf

[19] Atlas 410 Stainless Steel Grade Data Sheet, http://www.atlassteels.com.au/documents/Atlas\%20Grade\%20datasheet \%20410\%20rev\%20May\%202008.pdf

[20] J. E. Cousineau, , K. Bennion, D. DeVoto, and S. Narumanchi, "Experimental characterization and modeling of thermal resistance of electric machine lamination stacks," International Journal of Heat and Mass Transfer 129 (2019), pp. 152-159.

[21] A. A.Wereszczak, J. E. Cousineau, K. Bennion, et al. "Anisotropic Thermal Response of Packed Copper Wire.” ASME. J. Thermal Sci. Eng. Appl. 2017, doi: 10.1115/1.4035972

[22] W. Sixel, M. Liu, G. Nellis and B. Sarlioglu, "Cooling of Windings in Electric Machines via 3D Printed Heat Exchanger," 2018 IEEE Energy Conversion Congress and Exposition (ECCE), Portland, OR, 2018, pp. 229-235. doi: 10.1109/ECCE.2018.8557845 